\title{
A Systematic Literature Review of Cerebrospinal Fluid Biomarkers in Delirium
}

\author{
Roanna J. Hall ${ }^{a, b}$ Susan D. Shenkin ${ }^{a, b}$ Alasdair M.J. MacLullich ${ }^{a, b}$ \\ aEdinburgh Delirium Research Group, Geriatric Medicine, Division of Health Sciences, School of Clinical Sciences \\ and Community Health, and ${ }^{\mathrm{b} C e n t r e}$ for Cognitive Ageing and Cognitive Epidemiology, University of Edinburgh, \\ Edinburgh, UK
}

\section{Key Words}

Cerebrospinal fluid $\cdot$ Delirium $\cdot$ Neurotransmitters $\cdot$

Cytokines $\cdot$ Cortisol $\cdot$ Biomarkers

\begin{abstract}
Background: Cerebrospinal fluid (CSF) analysis has great potential to advance understanding of delirium pathophysiology. Methods: A systematic literature review of CSF studies of DSM or ICD delirium was performed. Results: In 8 studies of 235 patients, delirium was associated with: elevated serotonin metabolites, interleukin-8, cortisol, lactate and protein, and reduced somatostatin, $\beta$-endorphin and neuronspecific enolase. Elevated acetylcholinesterase predicted poor outcome after delirium and higher dopamine metabolites were associated with psychotic features. Conclusions: No clear conclusions emerged, but the current literature suggests multiple areas for further investigation with more detailed studies.

Copyright $\odot 2011$ S. Karger AG, Basel
\end{abstract}

References $13,16,18$ and 22-26 are all final articles included in the review. (c) 2011 S. Karger AG, Basel

$1420-8008 / 11 / 0322-0079 \$ 38.00 / 0$

Fax +41613061234 E-Mail karger@karger.ch www.karger.com

\section{Introduction}

Delirium is a serious acute neuropsychiatric syndrome affecting $11-42 \%$ of general medical inpatients [1]. The main features are acute onset and fluctuating course, inattention, altered level of arousal with psychomotor agitation or retardation, perceptual disturbance, and sleepwake cycle disturbance [2-4]. Delirium is associated with increased morbidity and mortality, and a greater risk of long-term cognitive decline $[1,5,6]$. However, despite its importance, the mechanisms of delirium are under-researched and remain largely obscure.

There are many hypotheses of the pathophysiology of delirium. These include: (1) direct brain insults such as hypoxia, ischaemia, metabolic derangement, cerebral infarction [2]; (2) neurotransmitter imbalance such as cholinergic deficiency or dopamine excess, which may be induced by several classes of drugs (e.g. anticholinergics, antidepressants, L-dopa) [7]; (3) dysregulation of the hypothalamic pituitary adrenal axis in the elderly leading to sustained high cortisol levels $[2,8]$; (4) hyper-responsiveness of brain immune cells to stimulation from peripheral inflammation, leading to increased neuroinflammation and exaggerated sickness behaviour syndrome [2]. These potential mechanisms are not mutually exclusive. 
Whatever the peripheral or indeed central precipitants are for delirium, understanding the central nervous system (CNS) changes associated with the syndrome is crucial. Examining cerebrospinal fluid (CSF) for evidence of these changes is potentially highly informative. However, there are obvious ethical and practical difficulties in obtaining CSF specimens in patients with delirium and such studies remain rare. This systematic literature review aimed to identify the current published literature examining CSF in delirium in order to summarise existing knowledge and to provide a rational basis for future studies.

\section{Methods}

Because all studies were observational in design, we devised a protocol based on the MOOSE (Meta-analysis Of Observational Studies in Epidemiology) [9] guidelines.

\section{Study Identification}

Two reviewers (R.J.H. and S.D.S.) sought studies published until 5 February 2011 that examined CSF in delirium. Studies were identified using a comprehensive textword and $\mathrm{MeSH}$-based electronic search of MEDLINE, EMBASE, PsycINFO, Web of Science (including conference proceedings), PubMed and the Evidence Based Medicine reviews database (including the Cochrane database of systematic reviews and the Cochrane central register of controlled trials). We used terms including 'delirium' or 'acute confusional state', and 'cerebrospinal fluid' or 'lumbar puncture' (for the full search strategy, see 'Appendix'). A Google ${ }^{\mathrm{TM}}$ search was also performed using the terms 'CSF' and 'delirium'. Additional search terms which encompassed the main families of biomarkers were also included in the searches in MEDLINE and EMBASE, but these retrieved very few additional citations, none of which were relevant, and therefore the simpler strategy was used. Additionally, we hand searched the bibliographies of relevant articles [9], performed a forward citation search in Web of Science for all studies examined, and contacted experts in the field via the European Delirium Association.

\section{Study Selection}

Inclusion criteria were: (1) that delirium was diagnosed using one of the following diagnostic criteria for delirium or acute confusional state: Diagnostic and Statistical Manual of Mental Disorders (DSM Third Edition; DSM Third Edition Revised; or DSM Fourth Edition) [4], International Classification of Diseases [10] or validated measures based on these criteria such as the Confusion Assessment Method [11]; (2) that we could extract data on biomarker findings in CSF in delirium; (3) studies investigating CSF in neuropsychiatric systemic lupus erythematosus (SLE) were included only where delirium was thought to be secondary to a cause other than neuropsychiatric SLE. Exclusion criteria were: (1) case reports; (2) studies involving delirium tremens or hepatic encephalopathy, or where neuropsychiatric SLE was the primary cause of delirium, due to the specific aetiologies and clinical features of those conditions.
Data Extraction and Synthesis

R.J.H. and S.D.S. independently performed the search and extracted the data, which was checked by A.M.J.M. We recorded (if available): (1) study design and provenance; (2) number and characteristics of patients and controls and comparability of patient and control groups; (3) method used to diagnose delirium; (4) delirium severity; (5) aetiology of delirium; (6) method of obtaining CSF (i.e. lumbar puncture (LP) or spinal anaesthetic); (7) biomarkers studied; (8) methods used for analysis; (9) main findings of the studies, with numerical data as far as possible; (10) statistical significance; (11) statistical methods; (12) whether biomarker findings were predictive of prognosis or other outcomes.

Assessment of Study Quality

Two authors (R.J.H. and S.D.S.) independently assessed all manuscripts that met the inclusion criteria. There is no gold standard validated method for assessing the quality of observational studies [12], but there is consensus that the three most fundamental domains are: (1) appropriate selection of participants; (2) appropriate measurement of variables; (3) appropriate control of confounding, as well as considering design-specific biases. We therefore discuss these quality criteria for each study in a narrative fashion.

\section{Results}

A total of 2,307 citations were identified (fig. 1), and following review of the title and/or abstract 68 articles were retrieved for detailed analysis. Seventy-one further articles were retrieved by hand-searching of reference lists; 28 of these were related to neuropsychiatric SLE and were not suitable for inclusion. One paper in press was included following expert advice [13], and 1 Japanese paper [14] and related abstract [15] were retrieved serendipitously from the bibliography of an unrelated delirium article. One hundred and forty-two articles were retrieved for detailed evaluation: 130 were excluded (fig. 1). Eight of the remaining 12 articles reported longitudinal data on four biomarkers examined in one study population [16-23]. We have included the 4 articles that reported the most complete data set for each biomarker $[16,18,22,23]$. Therefore, 8 articles are discussed, reporting data from 5 studies [13, 16, 18, 22-26] (table 1).

\section{Overview}

The articles included were four papers reporting data from a prospective cohort study conducted by Koponen et al. [16, 18, 22, 23], and single papers from 4 other prospective cohort studies [13, 24-26]. A total of 142 patients with delirium and 93 controls were studied. Studies used lumbar puncture to obtain CSF, apart from Pearson et al. 
Fig. 1. Flow diagram demonstrating the results of the electronic database searches, the bibliography searches and the study selection process. $\mathrm{LP}=$ Lumbar puncture.

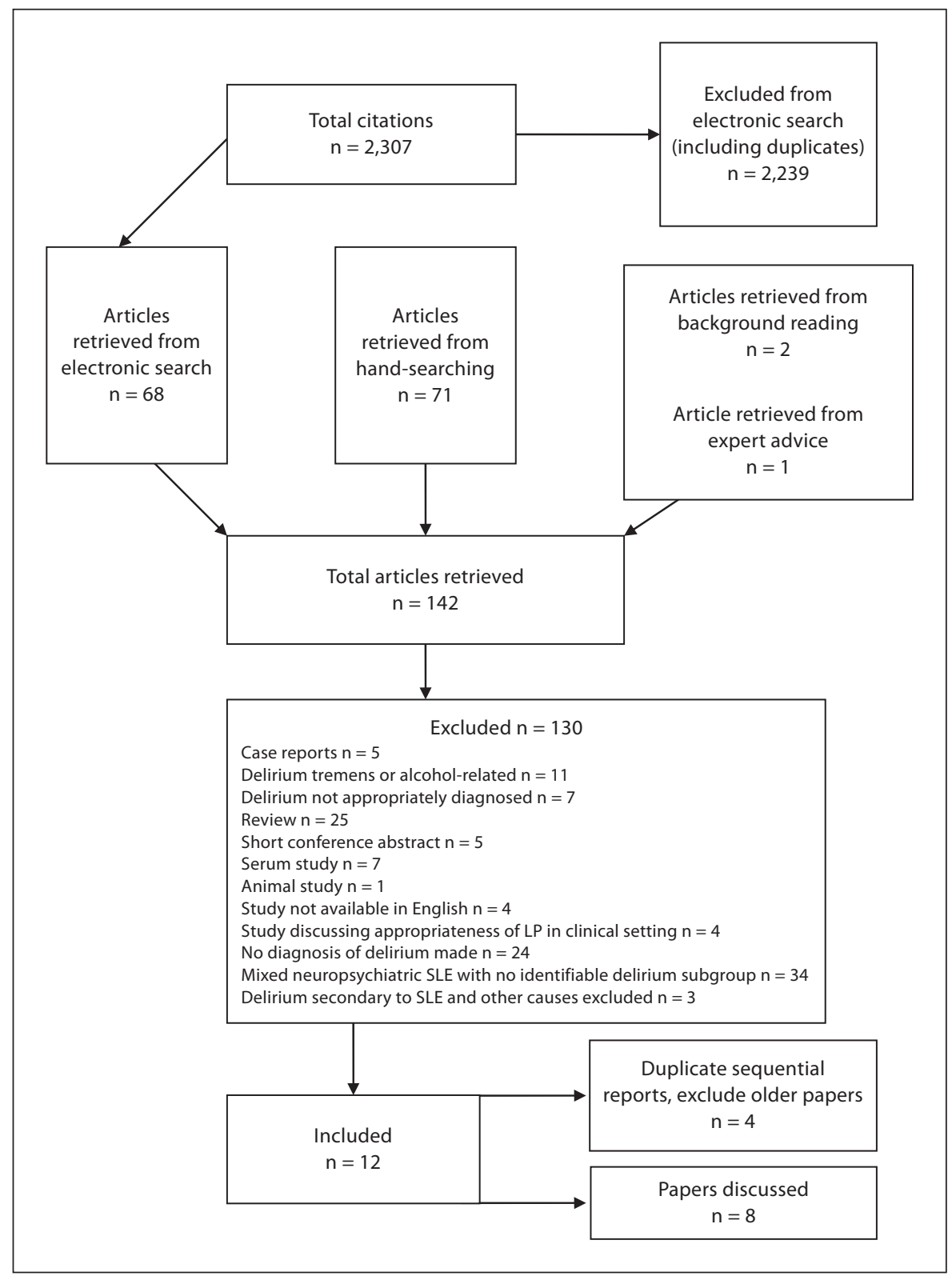

[25] and MacLullich et al. [13] where CSF was collected at the onset of spinal anaesthetic. A range of 17 different biomarkers were studied. Each of the articles relating to Koponen's study reported only one biomarker at various time-points and each research group focused on a different small set of biomarkers with no overlap among any of studies. Each result can only be considered in the context of the quality of that research study and the supporting evidence provided, and studies could not compared to each other for meta-analysis.

CSF in Delirium

\section{Additional Information on Individual Studies}

A narrative review outlining each study and summarising the main findings is presented below. Further detailed results are in table 1 .

Koponen et al.; Somatostatin, $\beta$-Endorphin, 5-Hydroxyindoleacetic Acid, Acetylcholinesterase

Koponen et al. [16, 18, 22, 23] undertook a prospective cohort study aiming to characterise the neurochemical features and long-term cognitive and functional outcomes of an aetiologically heterogeneous group of older 
Table 1a. Baseline characteristics of included studies

\begin{tabular}{|c|c|c|c|c|c|}
\hline Study/provenance & Design/setting & Biomarker(s) studied & Causes of delirium & Cases & Controls \\
\hline $\begin{array}{l}\text { Koponen et al. } \\
{[16,18,22,23]} \\
\text { Finland, 1990, } 1994\end{array}$ & $\begin{array}{l}\text { prospective cohort study, } \\
\text { with external control group; } \\
\text { psychogeriatric hospital }\end{array}$ & SLI, BLI, 5-HIAA, AChE & $\begin{array}{l}\text { stroke }(n=15) \text {, infection }(n=9) \text {, } \\
\text { metabolic }(n=8) \text {, epileptic fit }(n=6) \text {, } \\
\text { medication }(n=6) \text {, life change in } \\
\text { dementia }(n=5), \text { myocardial infarction } \\
\text { or ischaemia }(n=4) \text {, carcinoma }(n=4) \text {, } \\
\text { functional psychosis }(n=2) \text {, subdural } \\
\text { haematoma }(n=2) \text {, intracerebral } \\
\text { haemorrhage }(n=2) \text {, trauma }(n=2) \text {, } \\
\text { cerebral tumour }(n=1) \text {, aneurysm of } \\
\text { basilar artery and hydrocephalus }(n=1)\end{array}$ & $\begin{array}{l}\mathrm{n}=67 \text { for } \text { SLI } \\
(41.8 \% \text { male); } \\
\mathrm{n}=69 \text { for other bio- } \\
\text { markers }(42 \% \text { male); } \\
\mathrm{n}=56 \text { at } 2 \text { weeks; } \\
\mathrm{n}=33 \text { at } 1 \text { year; } \\
\mathrm{n}=16 \text { at } 4 \text { years; } \\
(11 \mathrm{LP})\end{array}$ & $\begin{array}{l}\mathrm{n}=13 \\
(38.5 \% \text { male }) \\
\text { for SLI, } \\
5 \text {-HIAA, } \\
\text { AChE } \\
\mathrm{n}=19(31.6 \% \\
\text { male) for BLI }\end{array}$ \\
\hline $\begin{array}{l}\text { Ramirez-Bermudez } \\
\text { et al. [24], Mexico, } 2008\end{array}$ & $\begin{array}{l}\text { prospective cohort study; } \\
\text { general hospital }\end{array}$ & HVA & primarily acute CNS infection & $\begin{array}{l}\mathrm{n}=31(54.9 \% \text { male } \\
\text { in whole group) }\end{array}$ & $\mathrm{n}=20$ \\
\hline $\begin{array}{l}\text { Pearson et al. [25] } \\
\text { Scotland, } 2010\end{array}$ & $\begin{array}{l}\text { prospective cohort study; } \\
\text { general hospital }\end{array}$ & cortisol & hip fracture and consequent surgery & $\begin{array}{l}\mathrm{n}=7(25 \% \text { male } \\
\text { in whole group })\end{array}$ & $\mathrm{n}=13$ \\
\hline $\begin{array}{l}\text { Caplan et al. [26] } \\
\text { Australia, } 2010\end{array}$ & $\begin{array}{l}\text { prospective cohort study; } \\
\text { general hospital }\end{array}$ & $\begin{array}{l}\text { lactate, NSE, S100B, } \\
\text { glucose, protein }\end{array}$ & heterogeneous acute medical illness & $\begin{array}{l}\mathrm{n}=20(\% \text { male } \\
\text { not stated })\end{array}$ & $\mathrm{n}=20$ \\
\hline $\begin{array}{l}\text { MacLullich et al. [13] } \\
\text { Scotland and } \\
\text { The Netherlands, } 2011\end{array}$ & $\begin{array}{l}\text { prospective cohort study; } \\
\text { general hospital }\end{array}$ & $\begin{array}{l}\text { TNF- } \alpha, \text { IL-1 } \beta, \text { IL-6, } \\
\text { IL- } 8, \text { IL-10 and IL-12p70 }\end{array}$ & hip fracture and consequent surgery & $\begin{array}{l}\mathrm{n}=15(\% \text { male } \\
\text { not stated })\end{array}$ & $\mathrm{n}=21$ \\
\hline
\end{tabular}

SLI = Somatostatin-like immunoreactivity; 5 -HIAA = hydroxyindole-acetic acid; AChE = acetyl-cholinesterase; HVA = homovanillic acid; $\mathrm{BLI}=\beta$-endorphinlike immunoreactivity; NSE = neuron-specific enolase; TNF- $\alpha=$ tumour necrosis factor-alpha; IL $=$ interleukin.

patients with delirium admitted to a psychogeriatric hospital in Finland. Participants were selected appropriately, since they consecutively recruited 70 older patients $(30$ men, $42.9 \%$ ), with a mean age of 75 years (range $60-88$ years). Diagnosis of delirium was based on DSM-III criteria. Patients with delirium tremens were excluded. Based on clinical assessment and CT brain scan, patients were categorised according to whether they met criteria for probable Alzheimer's dementia $(20 \%, \mathrm{n}=14)$, multiinfarct dementia $(57 \%, \mathrm{n}=40)$, Parkinson's disease $(4 \%$, $\mathrm{n}=3$ ) or whether they had no observable CNS disease $(19 \%, n=13)$. Patients underwent a morning fasting LP on the next working day following their index admission, 2 weeks after admission, and at 1 year and 4 years. There was no information on how long patients had been delirious prior to their admission and subsequent index LP. Data were only reported for some of the biomarkers from initial assessment through to the 4-year assessment. There was a significant rate of attrition, with 66 patients surviving to the LP at 2 weeks (6\% mortality), 33 of 44 surviving patients participating in 1-year follow-up $(37 \%$ mortality), and 16 of 24 surviving patients participating in 4-year follow-up (66\% mortality), of whom 5 refused to have an LP. There was no information on the reasons for other loss to follow-up. The control group used was drawn from a Healthy Ageing study at Kuopio University. A group of 19 controls was used for the $\beta$-endorphin study [18] and 13 controls for the somatostatin, 5-HIAA and acetylcholinesterase (AChE) studies [16, 22, 23]. Although age- and sex-matched, this set of controls was community dwelling and had no evidence of dementia and no psychoactive drug use, and therefore as a group differed from the delirium group which had a high proportion $(n=53 / 69,76.8 \%)$ of patients with probable dementia. Other issues identified in the quality assessment were that there was no evidence that the researcher analysing the CSF samples was blinded to the results, and there was no power calculation, although the statistical methods used were appropriate.

Koponen et al. [22] measured somatostatin-like immunoreactivity (SLI) in CSF by radioimmunoassay. Koponen found a reduction in mean SLI level for the whole delirious group at index, 2 weeks, 1 year and 4 years. They also found that SLI correlated with cognitive and functional performance: falling SLI correlated with worsening cognition (Mini-Mental State Examination, MMSE) from 2 weeks to 4 years, and with the level of daily functioning at 1 and 4 years. In the group with vascular dementia, SLI rose acutely in those with an acute stroke as the probable cause of their delirium; this may represent a response to injury or cerebral ischaemia [22]. In those whose delirium abated within the first 2 weeks, there was no change in the level of SLI. In the group with no observable CNS disease who could be seen as the closest to a de 
Table 1b. Summary of results at baseline

\begin{tabular}{|c|c|c|c|c|c|}
\hline Study & $\begin{array}{l}\text { Delirious } \\
\text { at LP, n }\end{array}$ & Main findings in delirious patients at baseline & Cases & Controls & $\mathrm{p}$ value \\
\hline $\begin{array}{l}\text { Koponen } \\
\text { et al. [22] }\end{array}$ & $67 / 67$ & $\begin{array}{l}\downarrow \text { SLI in whole delirious group; } \\
\downarrow \text { SLI in delirious group with no CNS disease }\end{array}$ & $\begin{array}{l}26.2 \pm 8.8 \mathrm{pg} / \mathrm{ml} \\
25.9 \pm 6.4 \mathrm{pg} / \mathrm{ml}\end{array}$ & $\begin{array}{l}37.6 \pm 9.8 \mathrm{pg} / \mathrm{ml} \\
37.6 \pm 9.8 \mathrm{pg} / \mathrm{ml}\end{array}$ & $\begin{array}{l}<0.001 \\
<0.001\end{array}$ \\
\hline $\begin{array}{l}\text { Koponen } \\
\text { et al. [18] }\end{array}$ & $69 / 69$ & $\begin{array}{l}\downarrow \text { BLI in whole delirious group; } \\
\downarrow \text { BLI in delirious group with no CNS disease }\end{array}$ & $\begin{array}{l}12.5 \pm 3.0 \mathrm{pg} / \mathrm{ml} \\
12.4 \pm 3.8 \mathrm{pg} / \mathrm{ml} \\
\end{array}$ & $\begin{array}{l}15.2 \pm 2.8 \mathrm{pg} / \mathrm{ml} \\
15.2 \pm 2.8 \mathrm{pg} / \mathrm{ml} \\
\end{array}$ & $\begin{array}{l}<0.001 \\
<0.05\end{array}$ \\
\hline $\begin{array}{l}\text { Koponen } \\
\text { et al. [16] }\end{array}$ & $69 / 69$ & $\begin{array}{l}\uparrow \text { in 5-HIAA vs. controls in those with delirium and no } \\
\text { CNS disease; association between 5-HIAA level and life span } \\
\text { after delirium (proportional hazards modeling) }\end{array}$ & $168.9 \pm 56.9 \mathrm{nmol} / \mathrm{l}$ & $118.1 \pm 34.9 \mathrm{nmol} / \mathrm{l}$ & $\begin{array}{l}<0.05 \\
0.007 \\
\mathrm{z}=2.93\end{array}$ \\
\hline $\begin{array}{l}\text { Koponen } \\
\text { et al. [23] }\end{array}$ & $69 / 69$ & $\begin{array}{l}\uparrow \mathrm{AChE} \text { in delirious patients who died during follow-up vs. } \\
\text { rest of cohort; } \\
\uparrow \mathrm{AChE} \text { in those requiring prolonged institutional care; } \\
\text { association between AChE and life span after delirium } \\
\text { (proportional hazards modeling) }\end{array}$ & $\begin{array}{l}22.0 \pm 8.0 \mathrm{nmol} / \mathrm{ml} / \mathrm{min} \\
21.0 \pm 5.9 \mathrm{nmol} / \mathrm{ml} / \mathrm{min}\end{array}$ & $\begin{array}{l}18.1 \pm 5.0 \mathrm{nmol} / \mathrm{ml} / \mathrm{min} \\
17.8 \pm 4.5 \mathrm{mnol} / \mathrm{ml} / \mathrm{min}\end{array}$ & $\begin{array}{l}0.005 \\
0.05 \\
0.019 \\
z=2.39 \\
\end{array}$ \\
\hline $\begin{array}{l}\text { Ramirez- } \\
\text { Bermudez } \\
\text { et al. [24] }\end{array}$ & $\begin{array}{l}\text { not stated; } \\
\text { LP within } \\
24 \text { h of } \\
\text { neuro-psy- } \\
\text { chological } \\
\text { assessment }\end{array}$ & $\begin{array}{l}\text { HVA not significantly different in delirium vs. non-delirium; } \\
\text { HVA } \uparrow \text { in those with hallucinations; } \\
\text { delusions; } \\
\text { antipsychotic treatment; } \\
\text { HVA } \downarrow \text { with HIV infection; } \\
\text { trend towards } \uparrow \text { HVA with agitation }\end{array}$ & $\begin{array}{l}300.8 \mathrm{nmol} / \mathrm{l}(36-1,915.7) \\
436.54 \mathrm{nmol} / \mathrm{l}(36-1,915.7) \\
490.5 \mathrm{nmol} / \mathrm{l}(36-1,915.7) \\
436.54 \mathrm{nmol} / \mathrm{l}(233.34-1,915.7) \\
118.72 \mathrm{nmol} / \mathrm{l}(36-496.85)\end{array}$ & $\begin{array}{c}231.65 \mathrm{nmol} / 1(36-1,062.3) \\
192.39 \mathrm{nmol} / \mathrm{l}(36-1,062.3) \\
157.4 \mathrm{nmol} / \mathrm{l}(36-1,062.3) \\
192.39 \mathrm{nmol} / 1(36-1,443.23) \\
314.25 \mathrm{nmol} / 1(36-1,915.7)\end{array}$ & $\begin{array}{l}0.108 \\
0.018 \\
0.001 \\
0.002 \\
0.006 \\
0.066 \\
\chi^{2} 5.45 \\
\end{array}$ \\
\hline $\begin{array}{l}\text { Pearson } \\
\text { et al. [25] }\end{array}$ & $7 / 20$ & $\begin{array}{l}\uparrow \text { CSF cortisol in delirium vs. controls; } \\
\uparrow \text { plasma cortisol in delirium vs. controls }\end{array}$ & $\begin{array}{c}63.9 \mathrm{nmol} / \mathrm{l}(40.4-102.1) \\
968.8 \mathrm{nmol} / 1(886.2-1,394.4)\end{array}$ & $\begin{array}{l}31.4 \mathrm{nmol} / \mathrm{l}(21.7-43.3) \\
809.4 \mathrm{nmol} / \mathrm{l}(544.0-986.4)\end{array}$ & $\begin{array}{l}0.029 \\
0.036\end{array}$ \\
\hline $\begin{array}{l}\text { Caplan } \\
\text { et al. [26] }\end{array}$ & $20 / 20$ & $\begin{array}{l}\text { in delirium vs. controls with Alzheimer’s dementia: } \\
\uparrow \text { CSF lactate; } \\
\downarrow \text { CSF neuron-specific enolase; } \\
\uparrow \text { CSF protein; } \\
\text { S100B no different; higher CSF lactate in delirium subgroup } \\
\text { who died in hospital vs. those discharged }\end{array}$ & $\begin{array}{c}1.87 \pm 0.31 \mathrm{mmol} / 1 \\
4.84 \pm 2.02 \mathrm{ng} / \mathrm{ml} \\
0.62 \pm 0.33 \mathrm{~g} / \mathrm{l} \\
604.8 \pm 163.0 \mathrm{pg} / \mathrm{ml} \\
2.15 \pm 0.17 \mathrm{mmol} / 1\end{array}$ & $\begin{array}{l}1.48 \pm 0.23 \mathrm{mmol} / \mathrm{l} \\
8.98 \pm 2.98 \mathrm{ng} / \mathrm{ml} \\
0.44 \pm 0.15 \mathrm{~g} / \mathrm{l} \\
697.4 \pm 306.9 \mathrm{pg} / \mathrm{ml} \\
1.77 \pm 0.26 \mathrm{mmol} / \mathrm{l}\end{array}$ & $\begin{array}{c}<0.001 \\
<0.001 \\
0.036 \\
0.33 \\
0.029\end{array}$ \\
\hline $\begin{array}{l}\text { MacLullich } \\
\text { et al. [13] }\end{array}$ & not stated & $\begin{array}{l}\uparrow \text { CSF IL- } 8 \text { in delirium vs. controls; } \\
\uparrow \text { serum IL-6 in delirium vs. controls; } \\
\text { TNF- } \alpha \text {, IL- } 1 \beta \text {, IL-10 and IL-12p70 not detected }\end{array}$ & $\begin{array}{l}69.8 \mathrm{pg} / \mathrm{ml}(47.9-125.6) \\
42.4 \mathrm{pg} / \mathrm{ml}(28.9-438.4)\end{array}$ & $\begin{array}{l}39.6 \mathrm{pg} / \mathrm{ml}(28.0-64.6) \\
24.3 \mathrm{pg} / \mathrm{ml}(0-217.2)\end{array}$ & $\begin{array}{l}0.003 \\
0.013\end{array}$ \\
\hline
\end{tabular}

Data presented as means \pm SD or medians (IQR). SLI = Somatostatin-like immunoreactivity; 5 -HIAA = hydroxyindole-acetic acid; AChE = acetyl-cholinesterase; $\mathrm{HVA}=$ homovanillic acid; $\mathrm{BLI}=\beta$-endorphin-like immunoreactivity.

Table 1c. Summary of results at follow-up

\begin{tabular}{|c|c|c|c|c|c|}
\hline $\begin{array}{l}\text { Time- } \\
\text { point }\end{array}$ & $\begin{array}{l}\text { Delirious } \\
\text { at LP, n }\end{array}$ & Main findings & $\begin{array}{l}\text { Cases } \\
{[\text { mean (SD)] }}\end{array}$ & $\begin{array}{l}\text { Controls } \\
\text { [mean (SD)] }\end{array}$ & $\mathrm{p}$ value \\
\hline \multirow[t]{8}{*}{2 weeks } & \multirow[t]{6}{*}{$14 / 66$} & $\downarrow$ SLI in whole delirious group; & $25.0 \pm 9.1 \mathrm{pg} / \mathrm{ml}$ & $37.6 \pm 9.8 \mathrm{pg} / \mathrm{ml}$ & $<0.001$ \\
\hline & & $\downarrow$ SLI in delirious group with no CNS disease; & $25.2 \pm 6.8 \mathrm{pg} / \mathrm{ml}$ & $37.6 \pm 9.8 \mathrm{pg} / \mathrm{ml}$ & $<0.01$ \\
\hline & & SLI unchanged in group with resolved delirium; & $25.4 \pm 8.8 \mathrm{pg} / \mathrm{ml}$ & $25.3 \pm 9.6 \mathrm{pg} / \mathrm{ml}$ & n.s. \\
\hline & & $\downarrow$ BLI in whole delirious group; & $12.1 \pm 4.3 \mathrm{pg} / \mathrm{ml}$ & $15.2 \pm 2.8 \mathrm{pg} / \mathrm{ml}$ & $<0.01$ \\
\hline & & BLI in delirious group with no CNS disease comparable with controls; & $14.4 \pm 6.2 \mathrm{pg} / \mathrm{ml}$ & $15.2 \pm 2.8 \mathrm{pg} / \mathrm{ml}$ & n.s. \\
\hline & & BLI unchanged in group with resolved delirium; & $12.2 \pm 3.5 \mathrm{pg} / \mathrm{ml}$ & $11.8 \pm 3.3 \mathrm{pg} / \mathrm{ml}$ & n.s. \\
\hline & $14 / 58$ & 5-HIAA unchanged in group with resolved delirium; & $161.9 \pm 121.2 \mathrm{nmol} / \mathrm{l}$ & $176.9 \pm 100.0 \mathrm{nmol} / 1$ & n.s. \\
\hline & $14 / 58$ & AChE unchanged in group with resolved delirium & $21.8 \pm 8.0 \mathrm{nmol} / \mathrm{ml} / \mathrm{min}$ & $21.2 \pm 6.2 \mathrm{nmol} / \mathrm{ml} / \mathrm{min}$ & n.s. \\
\hline \multirow[t]{6}{*}{1 year } & \multirow[t]{6}{*}{$0 / 33$} & $\downarrow$ SLI in whole delirious group; & $24.7 \pm 10.7 \mathrm{pg} / \mathrm{ml}$ & $37.6 \pm 9.8 \mathrm{pg} / \mathrm{ml}$ & $<0.001$ \\
\hline & & SLI in delirious group with no CNS disease comparable with controls; & $41.6 \pm 7.5 \mathrm{pg} / \mathrm{ml}$ & $37.6 \pm 9.8 \mathrm{pg} / \mathrm{ml}$ & \\
\hline & & SLI correlated with level of daily functioning; & & & $<0.01, \mathrm{r}=-0$ \\
\hline & & $\downarrow$ BLI in whole delirious group; & & & $<0.001$ \\
\hline & & BLI in delirious group with no CNS disease comparable with controls; & $10.8 \pm 3.2 \mathrm{pg} / \mathrm{ml}$ & $15.2 \pm 2.8 \mathrm{pg} / \mathrm{ml}$ & n.s. \\
\hline & & 5-HIAA and MMSE positively correlated & $13.4 \pm 4.8 \mathrm{pg} / \mathrm{ml}$ & $15.2 \pm 2.8 \mathrm{pg} / \mathrm{ml}$ & $<0.01, \mathrm{r}=0.43$ \\
\hline 4 years & $0 / 11$ & $\begin{array}{l}\downarrow \text { SLI in delirious group; } \\
\text { SLI correlated with level of daily functioning }\end{array}$ & $22.9 \pm 5.8 \mathrm{pg} / \mathrm{ml}$ & $37.6 \pm 9.8 \mathrm{pg} / \mathrm{ml}$ & $\begin{array}{l}<0.001 \\
<0.01, r=-0.75\end{array}$ \\
\hline
\end{tabular}

Data from: Koponen et al. $[16,18,22,23]$. SLI = Somatostatin-like immunoreactivity; 5-HIAA = hydroxyindole-acetic acid; AChE = acetyl-cholinesterase; $\mathrm{HVA}=$ homovanillic acid; BLI $=\beta$-endorphin-like immunoreactivity. 
Table 2. Subgroup means for 5-HIAA (nmol/l)

\begin{tabular}{llllll}
\hline & Multi-infarct dementia & $\begin{array}{l}\text { Alzheimer's } \\
\text { dementia }\end{array}$ & $\begin{array}{l}\text { Parkinson's } \\
\text { disease }\end{array}$ & No CNS disease & Whole group \\
\hline Baseline & $\begin{array}{l}174.6 \pm 87.7 \\
\mathrm{n}=39, \mathrm{p}<0.05 \text { vs. controls }\end{array}$ & $\begin{array}{l}173.6 \pm 238.0 \\
\mathrm{n}=14\end{array}$ & $\begin{array}{l}150.1 \pm 56.8 \\
\mathrm{n}=3\end{array}$ & $\begin{array}{l}168.9 \pm 56.9 \\
\mathrm{n}=13, \mathrm{p}<0.05 \text { vs. controls }\end{array}$ & $\begin{array}{l}172.3 \pm 125.8 \\
\mathrm{n}=69\end{array}$ \\
\hline 2 weeks & $190.9 \pm 137.4$ & $\begin{array}{l}101.6 \pm 6.9 \\
\mathrm{n}=12\end{array}$ & $\begin{array}{l}131.6 \pm 31.3 \\
\mathrm{n}=3\end{array}$ & $\begin{array}{l}154.6 \pm 50.3 \\
\mathrm{n}=7\end{array}$ & $\mathrm{n}=58$ \\
\hline 1 year & $\mathrm{n}=36$ & $106.9 \pm 46.8$ & $\begin{array}{l}145.3 \pm 94.8 \\
\mathrm{n}=3\end{array}$ & $\begin{array}{l}184.6 \pm 84.6 \\
\mathrm{n}=5, \mathrm{p}<0.05 \text { vs. controls }\end{array}$ & $\begin{array}{l}142.5 \pm 73.2 \\
\mathrm{n}=33\end{array}$ \\
\hline
\end{tabular}

Data from Koponen et al. [16]. Control group 5-HIAA level $=118.1 \pm 34.9 \mathrm{nmol} / \mathrm{l}(\mathrm{n}=13)$.

novo delirium episode, SLI was significantly low up to 2 weeks, rising to a level comparable with the control group at 1 and 4 years. In summary, loss of somatostatin signaling appears to have a role in dementia and transient loss may be implicated in delirium.

$\beta$-Endorphin-like immunoreactivity (BLI) was measured by radioimmunoassay. The group found lower levels of mean BLI in the delirious group at index, 2 weeks and 1 year. BLI was lower in those with 'silent' or hypoactive and mixed delirium, severe cognitive decline and vascular dementia, but not Alzheimer's dementia. However, the numbers for some of these subgroup means were quite small (from 4 to 40 at baseline and 3 to 12 at 1 year) and it is unclear whether these were a priori or post hoc analyses. There was also a positive correlation between MMSE and BLI within the whole delirious group at the acute stage only, and in subgroups with hyperkinetic delirium, moderate cognitive decline and in those receiving psychoactive drugs. There was no change in BLI in those whose delirium had abated at the 2 -week point. However, in the group with no CNS disease there was a transient and apparently reversible fall in BLI at index, with a rise to levels comparable to controls at 1 year. In summary, there may be a fall in $\beta$-endorphin signaling in delirium, but it is difficult to conclude that these changes are related to delirium rather than dementia.

High-performance liquid chromatography with amperometric detection was used to measure 5-HIAA, the main metabolite of serotonin [16]. Mean 5-HIAA was higher only in delirious subgroups with vascular dementia or no apparent CNS disease (table 2). The levels stayed high at 2 weeks and 1 year in both groups. There was no reduction in 5-HIAA levels in those whose delirium abated. There was a positive correlation between 5-HIAA and
MMSE in the whole delirious population at 1 year (i.e. higher 5-HIAA associated with better score on MMSE). Interestingly, there was also an association between the index 5-HIAA level and life span after delirium $(z=2.93$, $\mathrm{p}=0.007)$, and patients needing prolonged institutional care had a lower 5-HIAA level acutely $(\mathrm{p}=0.01)$.

High levels of 5-HIAA in the group with vascular dementia may be related to release from ischaemic neurons, and many cases of delirium in the group with vascular dementia were attributed to acute stroke [16]. An alternative possibility might be small vessel disease. The findings in the group with no CNS disease support a possible role for excess serotoninergic activity or turnover in delirium, or perhaps a vascular aetiology for some episodes of delirium in patients with vascular dementia. There also seem to be prognostic implications of the association between low 5-HIAA in acute delirium and shorter life span after delirium and the need for prolonged institutional care.

A modification of a colorimetric method was used to measure AChE, the enzyme with a major role in metabolising acetylcholine [23]. There was no association between AChE and delirium in the delirious group as a whole. However, there was a fall in levels of AChE between the 2-week and 1-year time-points in the delirium subgroups with Alzheimer's dementia, multi-infarct dementia and hyperkinetic delirium (table 3). There was also a small but non-significant reduction in levels of $\mathrm{AChE}$ in the group with no CNS disease. There was no change in AChE level in those whose delirium abated. Higher baseline AChE levels predicted a need for prolonged institutional care, shorter life span and death during follow-up. In summary, lower AChE was associated with later dementia, but higher AChE was associated with poorer outcomes. The discrepancy between these results 
Table 3. Subgroup means for AChE (nmol/ml/min)

\begin{tabular}{|c|c|c|c|c|c|}
\hline & $\begin{array}{l}\text { Multi-infarct } \\
\text { dementia }\end{array}$ & $\begin{array}{l}\text { Alzheimer's } \\
\text { dementia }\end{array}$ & $\begin{array}{l}\text { Parkinson's } \\
\text { disease }\end{array}$ & No CNS disease & Whole group \\
\hline Baseline & $\begin{array}{l}22.6 \pm 8.2 \\
n=39\end{array}$ & $\begin{array}{l}21.1 \pm 7.0 \\
n=14\end{array}$ & $\begin{array}{l}18.9 \pm 2.1 \\
n=3\end{array}$ & $\begin{array}{l}17.9 \pm 4.4 \\
n=13 \\
p<0.01 \text { vs. controls }\end{array}$ & $\begin{array}{l}21.3 \pm 7.4 \\
n=69\end{array}$ \\
\hline 2 weeks & $\begin{array}{l}21.9 \pm 6.6 \\
n=36\end{array}$ & $\begin{array}{l}19.2 \pm 6.3 \\
n=12\end{array}$ & $\begin{array}{l}17.8 \pm 3.6 \\
n=3\end{array}$ & $\begin{array}{l}19.0 \pm 3.8 \\
n=7\end{array}$ & $\begin{array}{l}20.8 \pm 6.2 \\
n=58\end{array}$ \\
\hline 1 year & $\begin{array}{l}19.2 \pm 5.8 \\
\mathrm{n}=17 \\
\mathrm{p}<0.05 \text { vs. controls }\end{array}$ & $\begin{array}{l}17.7 \pm 5.1 \\
n=8 \\
p<0.05 \text { vs. controls }\end{array}$ & $\begin{array}{l}18.5 \pm 0.1 \\
n=3\end{array}$ & $\begin{array}{l}18.0 \pm 3.1 \\
n=5 \\
p<0.01 \text { vs. controls }\end{array}$ & $\begin{array}{l}18.0 \pm 3.1 \\
n=33 \\
p<0.001 \text { vs. controls }\end{array}$ \\
\hline 4 years & $\begin{array}{l}18.4 \pm 5.9 \\
\mathrm{n}=7\end{array}$ & $\begin{array}{l}17.7 \pm 2.8 \\
n=2\end{array}$ & & $\begin{array}{l}24.5 \pm 0.2 \\
n=2\end{array}$ & $\begin{array}{l}19.4 \pm 5.3 \\
n=11 \\
p<0.05 \text { vs. controls }\end{array}$ \\
\hline
\end{tabular}

Data from Koponen et al. [23]. Control group AChE level = 24.3 $\pm 6.2 \mathrm{nmol} / \mathrm{ml} / \mathrm{min}(\mathrm{n}=13)$.

makes it difficult to conclude whether high or low levels of the enzyme AChE are more indicative of delirium and poor outcomes.

Ramirez-Bermudez et al.; Homovanillic Acid

Ramirez-Bermudez et al. [24] conducted a prospective cohort study with the aim of determining if CSF homovanillic acid (HVA, a dopamine metabolite) levels are raised in delirium. They recruited 51 patients with acute neurological symptoms requiring LP over a 3-year period at a general hospital in Mexico. No exclusion criteria were cited, nor the number eligible who did not take part, and there is no evidence that sampling bias was minimised or that a power calculation was used. The mean age of the cohort was 36.4 years, with the range of $18-85$ years, and $54.9 \%$ were male. This cohort had a high proportion of CNS infections (43/51 patients). The other 8 patients had other neurological diagnoses. There was also a relatively high rate of HIV infection (16/51 patients). These aetiological factors may have confounded the results. The investigators used the Spanish translation of the Delirium Rating Scale [27, 28], and delirium was diagnosed based on DSM-IV criteria by a trained clinical neuropsychiatrist. Although the assessment included informant history, no comment was made on premorbid cognition. The authors stated that age was not significantly different between the groups. There was no other external control group. Lumbar puncture was performed within $24 \mathrm{~h}$ of neuropsychological assessment. Only the results pertaining to CSF HVA levels were reported in the included pa- per. However, a conference abstract from these authors reported that they had also measured neurochemical metabolites of serotonin, nitric oxide and the amino acids GABA, glutamate, glutamine and glycine, but that levels of these were not significantly different in those with delirium or psychotic features [29]. No further published details of these additional measurements appear to be available.

Ramirez-Bermudez et al. [24] used high-performance liquid chromatography with electrochemical detection to measure HVA. Although HVA was not significantly different between those with and without delirium, HVA was found to be higher with psychotic features such as hallucinations and delusions (table 1b). HVA was also significantly related to the total Delirium Rating Scale score and to scores on subtests rating psychotic features, cognitive dysfunction and symptom fluctuation. In subgroup analyses, those without anti-psychotic exposure $(n=38)$ had higher HVA correlated with delusions. In those with acute viral encephalitis $(n=23)$, HVA was higher in those with psychotic features. In those who were HIV negative $(\mathrm{n}=35)$, HVA was higher with psychotic features, hallucinations and delusions. Regardless of delirium status, HVA levels were also significantly higher in HIV-negative patients and in those who had received anti-psychotic medication. These results suggest excess dopamine signaling may be involved in psychotic features, and perhaps in delirium pathogenesis overall [24]. However, this was a cohort study of patients requiring lumbar puncture for clinical reasons; therefore, those who developed delirium 
and those who did not were not comparable at baseline, and causation cannot be inferred.

\section{Pearson et al.; Cortisol}

Pearson et al. [25] undertook a prospective cohort study in patients over the age of 60 undergoing spinal anaesthetic for repair of a hip fracture, with the aim of determining if CSF cortisol levels are elevated in delirium. The setting was a university hospital in Scotland. They recruited 27 patients preoperatively; however, because of a change to general anaesthetic and blood contamination of CSF, 20 patients were included in the analyses. No power calculation was stated and they did not attempt to minimise sampling bias. The cohort was mainly female (75\%) and had a mean age of 80.6 years (range 62-93 years). The age of patients with delirium was not significantly different from controls $(81.4 \pm 7.2$ vs. $80.5 \pm 8.7$ years, $\mathrm{p}=0.88$ ). There was no other comment on the comparability of cases and controls, although further information on co-morbid disease was provided in table format. No external control group was used. Patients were assessed for delirium preoperatively with a validated assessment battery which informed completion of the Confusion Assessment Method (CAM) [11] which is based on DSM-IIIR criteria. There was no assessment made of prior cognition. CSF specimens were taken at the onset of spinal anaesthetic, before administration of the anaesthetic agent. Cortisol levels were measured by ELISA and in a paired plasma sample by cortisol- ${ }^{125}$ I radioimmunoassay. The researcher was not blinded to the participants' diagnoses. The investigators found CSF cortisol levels to be higher in those with delirium than those without [median (IQR) $63.9(40.4-102.1) \mathrm{nmol} / 1$ in delirium vs. 31.4 $(21.7-43.3) \mathrm{nmol} / \mathrm{l}$ in controls), $\mathrm{p}=0.029]$. Plasma cortisol was also significantly higher in cases than controls [25]. This suggests an association between elevated CSF cortisol and delirium [30, 31], although causation could not be inferred in this cross-sectional observational study. As the authors commented [25], dementia, severity of co-morbid disease and physiological stress are potential confounding factors which should be assessed in future studies.

\section{Caplan et al.; Markers of Neuronal Cell Death}

Caplan et al. [26] undertook a prospective cohort study in a geriatric medicine unit in a general hospital in Australia. Their patient group had persistent delirium of longer than 5 days' duration, where further investigation including LP was deemed to be clinically appropriate and was agreed by the patient and/or their proxy.
Twenty patients with heterogeneous delirium were recruited. Although no power calculation is cited, they attempted to minimise sampling bias. The aim was to compare CSF, blood and clinical markers of delirium and neuronal cell death between patients with delirium and an external control group of outpatients with known Alzheimer's Dementia but no delirium $(n=20)$. There was no inpatient control group. The two groups were relatively well-matched: age was not significantly different $(81.6 \pm 7.7$ years in the delirium group and $81.1 \pm$ 6.1 years in the dementia group), and instrumental activities of daily living, Charlson Index (a measure of comorbidity), Informant Questionnaire on Cognitive Decline in the Elderly and Geriatric Depression Score were not significantly different. However, the fact that the average Informant Questionnaire on Cognitive Decline in the Elderly score in the delirium group was the same as in the dementia group (3.7 in both groups) suggests a high prevalence of dementia in the delirium group. Delirium was diagnosed using the Confusion Assessment Method and Delirium Index. The Acute Physiology, Age, Chronic Health Evaluation (APACHE III) score, used for risk prediction in the severely ill, was significantly higher in the delirium group. LP was performed during the delirium episode or on an outpatient basis for the dementia group. CSF lactate, protein and glucose were measured at the local area laboratory and S100B and neuron-specific enolase were measured by ELISA, but no comment was made on whether there was blinding to participants' diagnoses.

The investigators found higher CSF lactate in the inpatient group with delirium compared to the outpatient group with Alzheimer's dementia (1.87 vs. $1.48 \mathrm{mmol} / \mathrm{l}$, $\mathrm{p}<0.001$ ), lower neuron-specific enolase (NSE) (4.84 vs. $8.98 \mathrm{ng} / \mathrm{ml}, \mathrm{p}<0.001)$, higher protein, and no difference in S100B and glucose [26]. In all participants, CSF lactate correlated positively with APACHE III score, CAM and Delirium Index. NSE correlated negatively with CAM and Delirium Index. CSF lactate correlated with a greater deterioration in scores of daily function (instrumental activities of daily living, and trend to correlation with Barthel index). Those within the delirium group who died in hospital had higher CSF lactate than those discharged home, and those who required institutional care had an intermediate level. The finding that CSF lactate was higher in persistent delirium, and was also associated with poorer outcomes, suggested that delirium may be associated with neuronal injury, or failure of normal aerobic energy metabolism such as ischaemia. However, here the group with delirium was 
acutely unwell, compared to the group with dementia who were stable outpatients; therefore, differences may be due to acute illness rather than delirium. A third group with acute illness but without delirium would have strengthened the study, as the group commented. The finding of high protein is relatively non-specific, and may indicate inflammation, trauma, infection or blood contamination [32]. The somewhat surprising finding of lower NSE in delirium in the context of high lactate was explained by the investigators as possibly due to lactate suppressing NSE. This could occur via glutamate stimulation suppressing glycolysis in neurons, which instead gain energy from astrocytic lactate, as per the shuttle hypothesis [26], but these findings require replication in other studies.

\section{MacLullich et al.; Cytokines}

MacLullich et al. [13] undertook a prospective cohort study in patients over the age of 60 years undergoing hip fracture repair under spinal anaesthesia, with the aim of investigating whether CNS proinflammatory cytokines are elevated in delirium. This was on a background of prior studies reporting elevated serum proinflammatory cytokines such as IL- 6 and IL-8. Thirty-six patients were recruited in University-affiliated medical centres in Edinburgh and Amsterdam. No power calculation is cited, and there was no comment on whether they attempted to minimise sampling bias. The mean age was 81.8 years in the group with delirium and 82.5 years in the group without, which was not significantly different. Charlson co-morbidity indices were not significantly different between the groups, but a documented history of dementia $(n=7)$ was associated with a higher incidence of delirium. There was no external control group. Patients were assessed for delirium preoperatively and 3-4 days postoperatively using the CAM. There was no assessment of inter-rater reliability between the two centres. CSF specimens were taken at the onset of spinal anaesthesia prior to the administration of anaesthetic agent. Cytokine analysis of CSF samples, and paired serum samples from the Edinburgh patients $(\mathrm{n}=$ 16), was performed using a Cytometric Bead Array immunoassay in the Edinburgh laboratory, although the researcher was not blinded to the participants' diagnoses. This measured TNF- $\alpha$, IL-1 $\beta$, IL-6, IL-8, IL-10 and IL-12p70. The investigators found IL- 8 to be detected in $33 / 36$ CSF samples, and IL-6 in 3/36 samples. The other cytokines were not detected. CSF IL-8 was significantly higher in cases than controls (median 69.8 vs. $39.6 \mathrm{pg} /$ $\mathrm{ml}, \mathrm{p}=0.003)$. Cases also had higher serum IL-6 levels (median 42.4 vs. $24.3 \mathrm{pg} / \mathrm{ml}, \mathrm{p}=0.013$ ). Dementia was not associated with raised IL- 8 , and when the investigators excluded patients with known dementia from the analysis, the pattern of results did not change. These results suggest an association between delirium and elevated CNS IL-8, although causation cannot be implied in this cross-sectional observational study.

\section{Discussion}

This is the first systematic literature review of studies examining CSF biomarkers in delirium. The quality of all studies is reported in a narrative fashion as there is no accepted gold standard tool for assessing quality and susceptibility to bias in observational studies [12], and there are potential concerns that scoring systems may be spuriously precise [33]. All studies were prospective studies, designed to investigate CSF biomarkers in delirium, which used appropriate statistical methods. None reported power calculations. Only one study blinded the researcher analysing the CSF samples to the clinical status of the patient [24]. Several of the studies' results could have been influenced by bias or confounding, and these are reported with their results above. Sample sizes were generally small, and a diverse range of populations was studied even within the five main studies. Within the heterogeneous elderly delirious populations of Koponen et al. $[16,18,22,23]$ and Caplan et al. [26] and the elderly cohorts with hip fracture and attendant co-morbidities of Pearson et al. [25] and MacLullich et al. [13], there is likely to be a high proportion of unrecognised dementia. The patients studied by Ramirez-Bermudez et al. [24] are a more homogeneous younger cohort (but which is less representative of the majority of inpatients with delirium). Where there is potential concomitant dementia, it is very difficult to determine whether observed changes are related to acute delirium or confounded by underlying dementia pathology [34]. A further potential confounding factor in these heterogeneous groups of patients is the underlying aetiology of delirium. These are common problems in studies of delirium pathophysiology. It is important that control groups are age-matched, to control for physiological changes with age; age-specific reference ranges for most biomarkers in CSF have not been determined, and many of these systems including the hypothalamic-pituitary-adrenal axis and immune system change with age [35-37]. Also, unless a biomarker is known only to originate from the CNS, co-measurement of the biomarker in a paired serum sample helps to estab- 


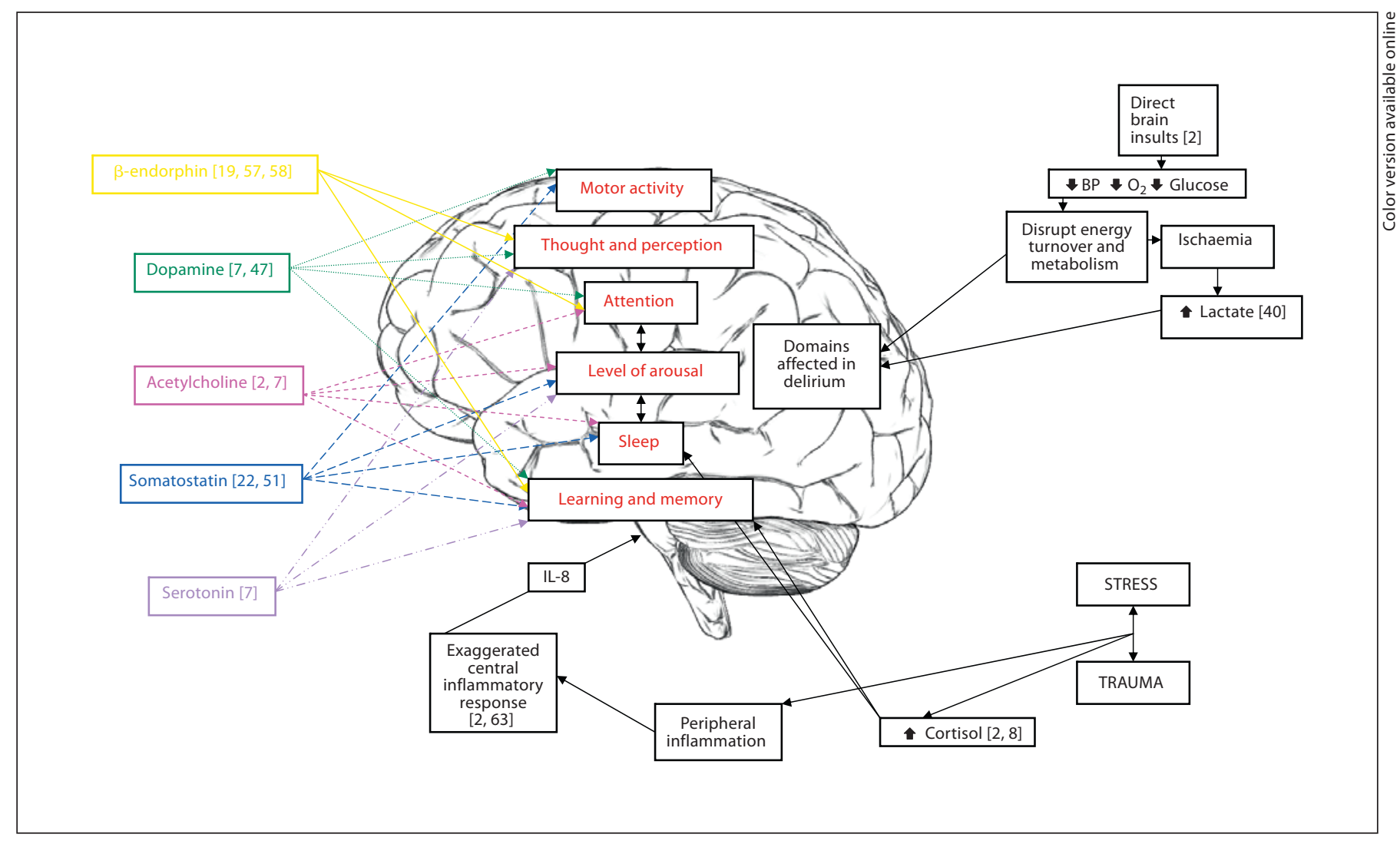

Fig. 2. This figure demonstrates a model of possible causal pathways in delirium, restricted to the results of this systematic review. $\mathrm{BP}=$ Blood pressure.

lish whether it has been produced predominantly in the CNS or whether high peripheral levels may have led, in some cases, to increased passage into the CNS, for example in the event of blood-brain barrier compromise in sepsis $[38,39]$. Serum values were reported by Pearson et al. [25], Caplan et al. [26] and MacLullich et al. [13].

The paucity of studies and their heterogeneous nature make it difficult to draw firm conclusions relating to CSF neurochemical disturbances in delirium which might shed light on pathophysiological processes. These studies suggest, however, the following possibilities in delirium: (1) a transient and reversible fall in both somatostatin and $\beta$-endorphin signalling, (2) increased serotoninergic signaling, (3) increased dopamine signaling involved in psychotic features, (4) high $\mathrm{AChE}$ as a predictor of poor outcome, (5) increased cortisol levels, (6) increased lactate and protein, (8) low neuron-specific enolase, (9) increased IL- 8 release; (10) TNF- $\alpha$, IL-1 $\beta$, IL-6, IL-10, IL-12p70 and S100B currently show no associations.
We now briefly discuss the relevance of these findings to the main hypotheses for delirium pathogenesis discussed earlier. For a putative model of causal pathways in delirium suggested by the results of this review, please see figure 2 .

\section{Direct Brain Insults}

None of the studies directly tested this theory since the aetiology of delirium is usually heterogeneous. Since many direct brain insults lead to a disruption of brain energy supply and metabolism, the finding of Caplan et al. [26] of raised CSF lactate suggests that a disruption of the brain's normal aerobic metabolism, either through low-grade ischaemia or a combination of factors, may be involved in delirium. Whether this is a cause or effect of delirium, or indeed a measure of how unwell the delirious patients are compared to controls, is unclear. Lactate is produced during ischaemia, when the lack of oxygen necessitates the switching of glycolytic metabolism from aerobic to anaerobic $[40,41]$, and high levels have also 
been found in CSF in dementia [42] and after out of hospital cardiac arrest [41]. The finding of low neuronspecific enolase (a glycolytic enzyme released following neuronal cell damage) was surprising, and the investigators suspect it to be due to lactate suppressing NSE - possibly via glutamate stimulation suppressing glycolysis in neurons, which instead gain energy from astrocytic lactate, as described in the astrocyte-neuron-lactate shuttle hypothesis [43].

\section{Neurotransmitter Imbalance}

Several of the studies lend support to this hypothesis. Serotonin, a monoamine neurotransmitter, has roles in mood, cognition and wakefulness, and excess or deficiency have been hypothesised to be involved in delirium [7]. The results of Koponen et al. [16] support an excess of serotonin, as does serotoninergic syndrome, clinically similar to delirium, where high levels of cerebral serotonin are caused by certain drugs [44]. Findings of an imbalance in levels of precursor amino acids for serotonin and other neurotransmitters also suggest a downstream role for serotonin $[45,46]$.

The association of high dopamine metabolites with psychotic features [24] supports a role in these symptoms of delirium, if not the whole syndrome. Dopamine has a role in motor activity, attention, memory, thought and perception [47], all domains which may be affected in delirium. The usefulness of $\mathrm{D}_{2}$ receptor inhibitors such as haloperidol in the treatment of psychotic symptoms of delirium [7] lends further support.

Disrupted cholinergic signaling with low acetylcholine has long been held to be one of the pathophysiologic mechanisms in delirium [7], and it has a well-established role in Alzheimer's dementia [48, 49]. The association of higher AChE with poorer outcomes after delirium may be related to a more severe initial delirium with greater acetylcholine release from degenerating neurons, or perhaps a tendency to higher levels of the enzyme initially leading to more severe delirium and poorer outcomes later on. Interestingly, low plasma AChE levels have been found in delirium in older medical in-patients [50].

The results for the neuropeptide hormones somatostatin and $\beta$-endorphin measured by Koponen et al. [18, $22]$ lend some support to a disruption in neurotransmission, but also possibly to a dysregulation in hypothalamic-pituitary signaling. Somatostatin is a hypothalamic peptide hormone with roles in the CNS in locomotion, sedation and excitation, sleep, learning and memory $[22$, 51]. A transient fall in levels may therefore be associated with acute changes in these domains, which may account for some features of delirium. Somatostatin forms part of the growth hormone-releasing hormone - growth hormone $(\mathrm{GH})$ - insulin-like growth factor 1 (IGF-1) axis, whereby somatostatin inhibits GH release from the pituitary. GH induces IGF-1 production and the pair work in synergy in target tissues [52]. IGF-1 has neurotrophic and anti-inflammatory properties and has been found to reduce tau phosphorylation and protect neurons from $\beta$ amyloid [53], and low serum IGF-1 is associated with incident and prevalent delirium $[54,55]$.

$\beta$-Endorphin is an endogenous opioid peptide $[56,57]$ released with ACTH from the anterior pituitary in response to stress $[57,58]$. In addition to its analgesic effect, it has a role in learning and memory [58], and possibly in sensory processing and selective attention. The locus coeruleus and limbic areas (important for these processes) have dense beta-endorphinergic innervation [19]. A transient fall may therefore disrupt vulnerable attentional processes and learning and memory. Interestingly, a study by McIntosh et al. [31] found a prolonged rise in plasma levels of $\beta$-endorphin and cortisol in a small cohort of patients with postoperative delirium. Decreased $\beta$-endorphin levels have been found in CSF in Parkinson's disease and Alzheimer's and multi-infarct dementia $[59,60]$, but normal levels have also been found in Alzheimer's dementia [61].

\section{Dysregulation of the Hypothalamic-Pituitary-}

\section{Adrenocortical Axis}

The findings of Pearson et al. [25] support the hypothesis that delirium is associated with elevated cortisol levels. Cortisol, the effector hormone of the hypothalamicpituitary-adrenal axis, forms part of the primary response of the body to stressful or traumatic insults [8]. Ageing and dementia are associated with an increased magnitude and duration of cortisol response to stress [2]. Prolonged hypercortisolaemia - seen in Cushing's disease, ageing and Alzheimer's dementia - is associated with atrophy of the hippocampus [8]. The hippocampus is involved in long-term potentiation critical for memory consolidation, and an intact hippocampus is important in negative feedback in the hypothalamic-pituitary-adrenal axis $[2,8]$. Prolonged hypercortisolaemia exacerbates the effects on neurons of hypoxia, ischaemia and hypoglycaemia and can increase vulnerability to cell death [47]. Higher plasma cortisol levels have been found in perioperative delirium [30]. Intriguingly, recent studies have found that in some circumstances, elevated glucocorticoids can have proinflammatory effects in the CNS [62]. 
Hyper-Responsiveness of Brain Immune Cells to Stimulation from Peripheral Inflammation

The findings of MacLullich et al. [13] support the idea that peripheral inflammatory insults may lead to an exaggerated central inflammatory response with increased sickness behaviour [2, 63]. Hip fracture is one such peripheral inflammatory insult, and the CSF levels of IL-8 found in the study were greater than those found peripherally, suggesting possible magnified CNS production. IL-8 is a generally proinflammatory chemokine, with a role in neutrophil chemotaxis. It is produced systemically and in the CNS. In vitro, IL-8 suppresses cultured septal cholinergic neurotransmission [64], and cerebral microinfusion of IL-8 into rats leads to anorexia and pyrexia [65]. IL-8 may also have protective effects, including a neuroprotective function, possibly by an antioxidant response pathway or by blocking apoptosis $[66,67]$.

\section{Limitations}

The results of this review highlight the scarcity of studies examining CSF in delirium. The cross-sectional designs preclude clear conclusions on the important question of whether any changes in biomarkers are the cause or the effects of the delirium. Results are reported on 17 biomarkers, but data may have been collected on others, and not published, leading to a publication bias.

This review was limited to studies published in the English language. We have not sought unpublished data. It is always possible to miss articles either with the search strategy or in searching the resulting citation lists. However, two individuals independently screened 2,307 citations derived from a search of six relevant and diverse databases, and we carefully hand-searched bibliographies and performed forward citation searches of all short-listed articles. We are therefore confident that no significant articles have been missed, and contact with leaders in the field of delirium research did not identify any other studies. We believe that the insistence that delirium be diagnosed by formal criteria is a strength of this review. Most of the included papers used DSM criteria for diagnosis of delirium apart from Pearson et al. [25] and MacLullich et al. [13] who used the CAM method which is based on DSM criteria.

\section{Implications for Future Research}

There is a clear need for further studies in this area, although this research faces several significant challenges. Studies attempting to understand the pathophysiology of delirium are limited by the heterogeneity of the clin- ical syndrome, the subjects' background (particularly preexisting, including undiagnosed, cognitive impairment), the cause and associated severity of illness, and the high associated mortality. Research is further limited by the care that must be taken in research with people who often do not have capacity to consent to participation in such studies [68], and in particular when an invasive investigation such as CSF examination is proposed. CSF sampling at spinal anaesthesia in orthopaedic or other surgery where delirium is prevalent affords a good opportunity to obtain CSF with minimal additional upset for the patient because the procedure is clinically necessary [25]. It is important though to avoid being too restrictive in performing LP for research purposes in delirium. Although this is an undeniably challenging procedure, the high prevalence and severity of delirium warrants this approach. Furthermore, delirium is a CNS disorder, albeit often precipitated by peripheral disease or injury. CSF analysis is commonly done for research purposes in patients with other CNS disorders (e.g. schizophrenia, depression, bipolar disorder, dementia, multiple sclerosis, epilepsy, traumatic brain injury and Creutzfeldt-Jakob disease [40, 69-74]), and this has led to significant advances of the fundamental knowledge of these disorders. We suggest that with sufficient care and selection of patients, studies of the CSF in delirium need not be restricted to opportunistic use of clinical samples or only where spinal anaesthesia is being performed. Proactive engagement with patient advocacy groups and research ethics committees will be necessary to help develop this crucial third route to obtaining CSF for delirium research.

Future studies need to be informed by prior research, use power calculations to ensure they will answer predefined hypotheses, clearly report the baseline characteristics of all subjects, and ensure blinding wherever possible. Ideally more generalisable populations of medical and surgical patients should be approached, with careful, standardised assessment of delirium and its severity and aetiology, and as much information on prior cognitive status as possible.

Future research should be guided by, but not limited to, biomarkers that have already been shown to be associated with delirium, and should also take cues from the main hypotheses of delirium pathophysiology and seek evidence of disrupted endocrine and inflammatory responses to stress as well as neurotransmitter upset. Of note, particularly in the case of neurotransmitters, a solitary CSF measurement provides only a snapshot which does not take into account the regional and minute-to- 
minute changes which may be taking place in different parts of the brain and spinal cord [75]. Analyses may also be limited by technical aspects, such as neurotransmitters which degrade too quickly to be accurately measured in vivo, e.g. acetylcholine [76, 77].

Given the morbidity and mortality associated with delirium and our increasing knowledge of its link with longer-term cognitive decline, information on potentially disordered neurotransmission, CNS inflammation and damaging prolonged hypercortisolaemia needs to be married with information on markers of CNS damage at the site of injury. Improved understanding of delirium pathophysiology, particularly with evidence of the mechanism of damage to the CNS, will likely provide better strategies for prevention and treatment of delirium in the future.

\section{Acknowledgements}

R.J.H. was funded by a Research Training Fellowship from Research into Ageing and the British Geriatrics Society. A.M.J.M. was funded by an MRC Clinician Scientist Fellowship. The authors are members of The University of Edinburgh Centre for Cognitive Ageing and Cognitive Epidemiology, part of the cross council Lifelong Health and Wellbeing Initiative (G0700704/84698). We would like to thank Sheila Fisken, liaison librarian for the College of Medicine and Veterinary Medicine, The University of Edinburgh for her help and advice designing the electronic search strategy and Maureen Harding, senior administrator in Geriatric Medicine, Division of Health Science, School of Clinical Sciences and Community Health, The University of Edinburgh for sourcing manuscripts.

All authors contributed significantly to the writing and revising of the manuscript. The manuscript has not been submitted elsewhere for publication. Data from earlier drafts of this systematic review have been published only as abstracts for conferences (Age and Ageing 2010, Volume 39, Suppl 2, p ii88 and at the European Delirium Association 5th Annual Scientific Congress, Amsterdam 2010).

\section{Disclosure Statement}

We have no conflicts of interest to declare.

\section{Appendix}

Search Strategy

EMBASE and EMBASE classic search: 861 abstracts on

5th February 2011

Database: 1947-2011 week 5

1 delir\$.tw OR Delirium/OR 'acute confusional state'.tw OR (acute adj3 conf\$).tw OR 'acute brain failure'.tw OR Acute Confusion/OR Confusion/

2 delirium tremens.ti

$3 \quad 1$ NOT 2

4 cerebrospinal fluid/OR cerebrospinal fluid.tw OR CSF.tw OR spinal puncture.mp OR lumbar puncture/OR lumbar puncture.tw

$5 \quad 3$ AND 4

Medline search: 233 abstracts on 5th February 2011

Database: 1948 to January week 42011

1 delir\$.tw OR 'acute confusional state'.tw OR (acute adj3 conf\$). tw OR 'acute brain failure'.tw OR exp Confusion/(includes Delirium/)

2 delirium tremens.ti

3 NOT 2

4 exp Cerebrospinal Fluid/OR cerebrospinal fluid.mp OR csf.tw OR Spinal Puncture/OR lumbar puncture.tw OR spinal puncture.tw

$5 \quad 3$ AND 4

Psychinfo search: 49 abstracts on 5th February 2011

Database: 1806 to February week 12011

1 delir\$.tw OR delirium/OR mental confusion/OR 'acute confusional state'.tw OR (acute adj3 conf\$).tw OR 'acute brain failure'.tw

2 delirium tremens.ti

31 NOT 2

4 csf.tw OR cerebrospinal fluid/OR cerebrospinal fluid.tw OR lumbar puncture.tw OR spinal puncture.tw

$5 \quad 3$ AND 4

Cochrane Library: 216 results on 5th February 2011, none relevant. Web of science (including conference papers) 1900-2011-02-05: 386 abstracts

Advanced search:

TS = (delirium OR 'acute confusional state' OR confusion OR 'acute brain failure' OR 'acute confusion') AND TS = (CSF OR 'cerebrospinal fluid' OR 'spinal puncture' OR 'lumbar puncture') PubMed search: 778 abstracts on 5th February 2011

(Delirium OR 'acute confusional state' OR confusion OR 'acute brain failure' OR 'acute confusion') AND (CSF OR 'cerebrospinal fluid' OR 'spinal puncture' OR 'lumbar puncture') 


\section{References}

$\checkmark 1$ Siddiqi N, House A, Holmes J: Occurrence and outcome of delirium in medical in-patients: a systematic literature review. Age Ageing 2006;35:350-364.

-2 MacLullich A, Ferguson K, Miller T, de Rooij $\mathrm{S}$, Cunningham C: Unravelling the pathophysiology of delirium: a focus on the role of aberrant stress responses. J Psychosom Res 2008;65:229-238.

3 Young J, Inouye S: Delirium in older people. BMJ 2008;334:842-846.

4 American Psychiatric Association: Diagnostic and Statistical Manual of Mental Disorders, Text Revision. Washington, APA, 2000.

$\checkmark 5$ Rockwood K, Cosway S, Carver D, Jarrett P, Stadnyk K, Fisk J: The risk of dementia and death after delirium. Age Ageing 1999;28: 551-556.

-6 MacLullich A, Beaglehole A, Hall R, Meagher D: Delirium and long-term cognitive impairment. Int Rev Psychiatry 2009;21: $30-42$.

7 Flacker J, Lipsitz L: Neural mechanisms of delirium: current hypotheses and evolving concepts. J Gerontol 1999;54A:B239-B246.

8 Olsson T: Activity in the hypothalamic-pituitary-adrenal axis and delirium. Dement Geriatr Cogn Dis 1999;10:345-349.

$\checkmark 9$ Stroup D, Berlin J, Morton S, Olkin I, Williamson G, Rennie D, Moher D, Becker B, Sipe T, Thacker S: Meta-analysis of observational studies in epidemiology - a proposal for reporting. J Am Med Assoc 2000;283: 2008-2012.

10 The ICD-10 Classification of Mental and Behavioural Disorders: Clinical Descriptions and Diagnostic Guidelines. Geneva, World Health Organisation, 1992.

-11 Inouye S, Vandyck C, Alessi C, Balkin S, Siegal A, Horowitz R: Clarifying confusion the confusion assessment method - a new method for detection of delirium. Ann Intern Med 1990;113:941-948.

12 Sanderson S, Tatt I, Higgins J: Tools for assessing quality and susceptibility to bias in observational studies in epidemiology: a systematic review and annotated bibliography. Int J Epidemiol 2007;36:666-676.

-13 MacLullich A, Edelshain B, Hall R, de Vries A, Howie S, Pearson A, Middleton S, Gillies F, Armstrong I, White T, Cunningham C, de Rooij S, van Munster B: Cerebrospinal IL-8 levels are higher in hip fracture patients with delirium versus controls. J Am Geriatr Soc 2011;59:1151-1153.

14 Tanaka K, Mitsushio H, Isse K: A clinical study of prostaglandin $\mathrm{D}_{2}$ in cerebrospinal fluid of elderly patients with delirium. Ann Rep Pharmacopsychiat Res Found 1993;24: $14-21$.

15 Tanaka K: Increased levels of prostaglandin $\mathrm{D}_{2}$ in cerebrospinal fluid of elderly patients with delirium. Jpn J Psychiatry Neurol 1993; 47:695-696.
6 Koponen H, Lepola U, Leinonen E: A longterm follow-up study of cerebrospinal fluid 5-hydroxyindoleacetic acid in delirium. Eur Arch Psychiatry Clin Neurosci 1994;244: 131-134.

17 Koponen H, Sirvio J, Reinikainen K, Riekkinen P: A longitudinal study of cerebrospinal fluid acetylcholinesterase in delirium: changes at the acute stage and at one-year follow-up. Psychiatry Res 1991;38:135-142.

18 Koponen H, Riekkinen P: A long-term follow-up study of cerebrospinal fluid beta-endorphin-like immunoreactivity in delirium: changes at the acute stage and at one-year follow-up. Acta Psychiatr Scand 1990;82: 323-326.

19 Koponen H, Stenback U, Mattila E, Reinikainen K, Soininen H, Riekkinen P: CSF beta-endorphin-like immunoreactivity in delirium. Biol Psychiatry 1989;25:938-944.

20 Koponen H, Stenback U, Mattila E, Reinikainen K, Soininen H, Riekkinen P: Cerebrospinal fluid somatostatin in delirium. Psychol Med 1989;19:605-609.

21 Koponen H, Reinikainen K, Riekkinen P: Cerebrospinal fluid somatostatin in delirium. II. Changes at the acute stage and at one year follow-up. Psychol Med 1990;20:501505.

-22 Koponen H, Leinonen E, Lepola U, Riekkinen P: A long-term follow-up study of cerebrospinal fluid somatostatin in delirium. Acta Psychiatr Scand 1994;89:329-334

23 Koponen H, Sirvio J, Lepola U, Leinonen E: A long-term follow-up study of cerebrospinal fluid acetylcholinesterase in delirium. Eur Arch Psychiatry Clin Neurosci 1994; 243:347-351.

24 Ramirez-Bermudez J, Ruiz-Chow A, PerezNeri I, Soto-Hernandez J, Flores-Hernandez R, Nente F, Montes S, Rios C: Cerebrospinal fluid homovanillic acid is correlated to psychotic features in neurological patients with delirium. Gen Hosp Psychiatry 2008;30:337343.

25 Pearson A, de Vries A, Middleton S, Gillies F, White T, Armstrong I, Andre R, Seckl J, MacLullich A: Cerebrospinal fluid cortisol levels are higher in patients with delirium versus controls. BMC Res Notes 2010;3:33.

26 Caplan G, Kvelde T, Lai C, Yap S, Lin C, Hill $\mathrm{M}$ : Cerebrospinal fluid in long-lasting delirium compared with Alzheimer's dementia. J Gerontol A Biol Med Sci 2010;65:1130-1136.

27 Secin R, Esponda J, Rivera B: Validacion del Delirium Rating Scale (DRS) en espanol en una unidad de cuidados intensivos. Psiquis 1998;7:7-14.

28 Trzepacz P, Baker R, Greenhouse J: A symptom rating scale for delirium. Psychiatry Res 1988;23:89-97.
29 Ramirez-Bermudez J, Camilo R, Perez-Neri I, Sergio M, Francisco N, Chow A: Neurochemical markers of delirium in cerebrospinal fluid of neurological patients with delirium. 26th Collegium Internationale NeuroPsychopharmacologicum Congress (CINP), Int J Neuropsychopharmacol 2008;11:296296.

30 Kudoh A, Takese H, Katagai H, Takazawi T: Postoperative interleukin- 6 and cortisol concentrations in elderly patients with postoperative confusion. Neuroimmunomodulation 2005;12:60-66.

-31 McIntosh T, Bush H, Yeston N, Grasberger R, Palter M, Aun F, Egdahl R: Beta-endorphin. Cortisol and postoperative delirium: a preliminary report. Psychoneuroendocrinology 1985;10:303-313.

32 Seehusen D, Reeves M, Fomin D: Cerebrospinal fluid analysis. Am Fam Physician 2003;68:1103-1108

$>33$ von Elm I: Assessing the quality of observational studies - or a lesson from Mars. Int J Epidemiol 2007;36:677-678.

34 Inouye S, Ferrucci L: Elucidating the pathophysiology of delirium and the interrelationship of delirium and dementia. J Gerontol Med Sci 2006;61A:1277-1280.

>35 Murakami K, Nakagawa T, Shozu M, Uchide $\mathrm{K}$, Koike $\mathrm{K}$, Inoue $\mathrm{M}$ : Changes with aging of steriodal levels in the cerebrospinal fluid of women. Maturitas 1999;33:71-80.

\36 Otte C, Hart S, Neylan T, Marmar C, Yaffe K, Mohr D: A meta-analysis of cortisol response to challenge in human aging: importance of gender. Psychoneuroendocrinology 2005;30:80-91.

37 Ginaldi L, Mengoli L, De Martinis M: Review on immunosenescence. Rev Clin Gerontol 2008;17:161-169.

38 Ballabh P, Braun A, Nedergaard M: The blood-brain barrier: an overview. Structure, regulation, and clinical implications. Neurobiol Dis 2004;16:1-13.

-39 Davies D: Blood-brain barrier breakdown in septic encephalopathy and brain tumours. J Anat 2002;200:639-646.

40 Petzold A: CSF biomarkers for improved prognostic accuracy in acute CNS disease. Neurol Res 2007;29:691-708.

41 Karkela J, Pasanen M, Kaukinen S, Morsky P, Harmoinen A: Evaluation of hypoxic brain injury with spinal fluid enzymes, lactate and pyruvate. Crit Care Med 1992;20: 378-386.

42 Parnetti L, Reboldi G, Gallai V: Cerebrospinal fluid pyruvate levels in Alzheimer's disease and vascular dementia. Neurology 2000;54:735-737.

43 Fillenz M: The role of lactate in brain metabolism. Neurochem Int 2005;47:413-417.

$\checkmark 44$ White S: The neuropathogenesis of delirium. Rev Clin Gerontol 2002;12:62-67. 
45 van der Mast R, Fekkes D, Moleman P, Pepplinkhuizen L: Is postoperative delirium related to reduced plasma tryptophan? Lancet 1991;338:851-852.

46 Pandharipande P, Morandi A, Adams J, Girard T, Thompson J, Shintani A, Ely E: Plasma tryptophan and tyrosine levels are independent risk factors for delirium in critically ill patients Intensive Care Med 2009;35: 1886-1892.

-47 Trzepacz P: Is there a final common neural pathway in delirium? Focus on acetylcholine and dopamine. Semin Clin Neuropsychiatry 2000;5:132-148.

48 Talesa V: Acetylcholinesterase in Alzheimer's disease. Mech Ageing Dev 2001;122: 1961-1969.

49 Birks J: Cholinesterase inhibitors for Alzheimer's disease. Cochrane Database Systemat Rev 2006;CD005593.

50 White S, Calver B, Newsway V, Wade R, Patel S, Bayer A, O'Mahoney M: Enzymes of drug metabolism during delirium. Age Ageing 2005;34:603-608.

51 Vecsai L, Widerlov E: Preclinical and clinical studies with somatostatin related to the central nervous system. Prog Neuropsychopharmacol Biol Psychiat 1990;14:473-502.

52 Murray R, Kim K, Ren S-G, Chelly M, Umehara Y, Melmed S: Central and peripheral actions of somatostatin on the growth hormone-IGF-1 axis. J Clin Investigat 2004;114: 349-356.

53 Broadhurst C, Wilson K: Immunology of delirium: new opportunities for treatment and research. Br J Psychiatry 2001;179.

-54 Adamis D, Lunn M, Martin FC, Treloar A, Gregson N, Hamilton G, MacDonald AJD: Cytokines and IGF-1 in delirious and nondelirious acutely ill older medical inpatients. Age Ageing 2009;38:326-332.

55 Wilson K, Broadhurst C, Diver M, Jackson M, Mottram P: Plasma insulin-like growth factor-1 and incident delirium. Int J Geriatr Psychiatry 2005;20:154-159.
56 Wollemann M, Benyhe S: Non-opioid actions of the opioid peptides. Life Sci $2004 ; 75$ : 257-270.

57 O’Donahue T, Dorsa D: The opiomelanotropinergic neuronal and endocrine systems. Peptides 1982;3:353-395.

58 Zager E, Black P: Neuropeptides in human memory and learning processes. Neurosurgery 1985; 17:355-369.

59 Jolkkonen J, Soininen H, Riekkinen P: Betaendorphin-like immunoreactivity in cerebrospinal fluid of patients with Alzheimer's dementia and Parkinson's disease. J Neurol Sci 1987;77:153-159.

60 Sulkava R, Erkinjuntti T, Laatikainen T: CSF beta-endorphin and beta-lipotropin in Alzheimer's disease and multi-infarct dementia. Neurology 1985;35:1057-1058.

61 Raskind M, Peskind E, Lampe T, Risse S, Taborsky G, Dorsa D: Cerebrospinal fluid vasopressin, oxytocin, somatostatin and betaendorphin in Alzheimer's disease. Arch Gen Psychiatry 1986;43:382-388.

62 Munhoz C, Sorrells S, Caso J, Scavone C, Sapolsky R: Glucocorticoids exacerbate lipopolysaccharide-induced signaling in the frontal cortex and hippocampus in a dosedependent manner. J Neurosci 2010;30 13690-13698.

63 Perry V, Cunningham C, Holmes C: System ic infections and inflammation affect chronic neurodegeneration. Nat Rev Immunol 2007;7:161-167.

64 Puma C, Danik M, Quirion R, Ramon F, Williams $\mathrm{S}$ : The chemokine interleukin8 acutely reduces $\mathrm{CA}^{2+}$ currents in identified cholinergic septal neurons expressing CXCR1 and CXCR2 receptor mRNAs. J Neurochem 2001;78:960-971.

65 Platasalaman C, Borkoski J: Interleukin-8 modulates feeding by direct action in the central nervous system. Am J Physiol 1993; 265:R877-R882.

66 Hussein M, Daoud G, Kakita H, Kato S, Goto T, Kamei M, Goto K, Nobata M, Ozaki Y, Ito T, Fukuda S, Kato I, Suzuki S, Sobajima HF, Hashimoto T, Togari H: High cerebrospinal fluid antioxidants and interleukin 8 are protective of hypoxic brain damage in newborns. Free Rad Res 2010;44:422-429.
67 Hanson J, Bostick M, Campe C, Kodali P, Lee G, Yan J, Maher J: Transgenic overexpression of interleukin-8 in mouse liver protects against galactosamine/endotoxin toxicity. J Hepatol 2006;44:359-367.

68 Holt R, Siddiqi N, Young J: The ethics of consent in delirium studies. J Psychosom Res 2008;65:283-287.

-69 Zetterberg H: Biomarkers reflecting different facets of Alzheimer's dementia. Eur J Neurol 2008;15:1143-1144.

70 Schwarz E, Bahn S: Cerebrospinal fluid: identification of diagnostic markers for schizophrenia. Expert Rev Mol Diagn 2008; 8:209-216.

71 Gudmundsson P, Skoog I, Waern M, Blennow K, Zetterberg H, Rosengren L, Gustafson D: Is there a CSF biomarker profile related to depression in elderly women? Psychiatry Res 2010;176:174-178.

72 Regenold W, Phatak P, Marano C, Sassan A, Conley R, Kling M: Elevated cerebrospinal fluid lactate concentrations in patients with bipolar disorder and schizophrenia: implications for the mitochondrial dysfunction hypothesis. Biol Psychiatry 2009;65:489-494.

73 Awad A, Hemmer B, Hartung H-P, Kieseier B, Bennett J, Stuve O: Analyses of cerebrospinal fluid in the diagnosis and monitoring of multiple sclerosis. J Neuroimmunol 2010; 219:1-7.

74 van Everbroeck B, Boons J, Cras P: Cerebrospinal fluid biomarkers in Creutzfeldt-Jakob disease. Clin Neurol Neurosurg 2005;107: 355-360.

75 Hyland K: Clinical utility of monoamine neurotransmitter metabolite analysis in cerebrospinal fluid. Clin Chem 2008;54:633641.

76 Frolich L, Dirr A, Gotz M, Gsell W, Reichmann H, Riederer P, Maurer K: Acetylcholine in human CSF: methodological considerations and levels in dementia of the Alzheimer type. J Neural Transm 1998;105: 961-973.

77 Bender M: Kinetics of cholinesterase in blood and spinal fluid. Am J Physiol 1939; 126:180-187. 